\title{
Sensory cues and the suppression of reproduction in subordinate female marmoset monkeys, Callithrix jacchus
}

\author{
J. Barrett, D. H. Abbott* and L. M. George $\dagger$ \\ MRC/AFRC Comparative Physiology Research Group, Institute of Zoology, Zoological Society of \\ London, Regent's Park, London NW1 4RY, UK
}

\begin{abstract}
Subordinate female marmoset monkeys remain anovulatory and have low plasma concentrations of luteinizing hormone ( $\mathrm{LH}$ ) when maintained with their dominant females. Olfactory cues from the dominant female have been implicated in maintaining this reproductive suppression. Subordinate females that received either ablation of the vomeronasal organ (an accessory olfactory organ; $n=3$ ), ablation of the main olfactory epithelium $(n=4)$, or both lesions $(n=5)$ did not ovulate in the following 7 weeks while housed with their dominant female. Plasma LH concentrations following either or both lesions were similar to pre-lesion concentrations. Olfactory lesions (verified by histological and behavioural trials) did not impair reproductive activity, as olfactory-lesioned dominant females underwent ovarian cycles of similar duration to intact dominant females. Lesioned subordinate females $(n=6)$, maintained in visual-only contact with their dominant female and group ovulated $29.1 \pm 9.3$ days (mean \pm SEM) after physical separation from their dominant females; this first onset of ovulation was significantly delayed $(P<0.05)$ compared with intact subordinate females completely isolated from their dominant females and group (10.8 \pm 1.3 days, $n=8$ ). Behavioural and visual cues together with olfaction all appear to play important roles in maintaining the suppression of ovulation in subordinate female marmoset monkeys.
\end{abstract}

\section{Introduction}

In the wild and in captivity, marmoset monkeys form social groups in which only one female breeds (Abbott and Hearn, 1978; Stevenson, 1978; Hubrecht, 1984; Stevenson and Rylands, 1988). Studies of captive group-housed marmoset monkeys have revealed that there is a social hierarchy among females in which only the dominant or rank 1 female ovulates: her subordinates (ranks 2 and below) remain anovulatory (Abbott et al., 1981, 1988). Subordinate females have low, acyclic concentrations of plasma progesterone $\left(<10 \mathrm{ng} \mathrm{m}^{-1}\right)$ and plasma luteinizing hormone $\left(\mathrm{LH}_{;}<2 \mathrm{iu}^{-1}\right)$ and a diminished response of the anterior pituitary, in terms of LH release, to a single gonadotrophin-releasing hormone $(\mathrm{GnRH})$ challenge (Abbott $e t$ al., 1988). It has been suggested that the dominant female imposes a hypothalamic block to $\mathrm{GnRH}$ release upon her subordinate females, thus rendering her subordinates anovulatory (Abbott, 1988, 1989; Abbott et al., 1988). If subordinate females are removed from their dominant females, a rapid rise in the concentration of plasma LH occurs, followed by the onset of ovulation (Abbott et al., 1988). Conversely, returning subordinate females to their dominant females brings about a

*Present address and correspondence: Wisconsin Regional Primate Research Center, University of Wisconsin, 1223 Capitol Court, Madison, WI 53715-1299, USA.

†Present address: Department of Environmental and Preventive Medicine, St Bartholomew's Medical College, Charterhouse Square, London EC1 M6BQ, UK.

Revised manuscript received 6 May 1992 return to their anovulatory state and a fall in circulating $\mathrm{LH}$ concentrations.

When subordinate female marmoset monkeys were physically separated from all but olfactory cues from their dominant female, onset of ovulation was delayed compared with controls (receiving no olfactory stimuli). Thus pheromonal cues from the dominant female marmoset play a role in maintaining reproductive suppression in subordinate female marmosets (Barrett et al., 1990). However, the olfactory route through which these inhibitory cues are processed by subordinates is unknown. Marmoset monkeys possess both main olfactory epithelium (located bilaterally at the dorsal caudal end of the nasal septum), a vomeronasal organ (an accessory olfactory epithelium, which lies bilaterally to the nasal septum, between the nasal cavity and the hard palate) and a connecting duct between the two olfactory organs and the oral cavity (the nasopalatine canal; Beattie, 1927; Harrison, 1987; C. J. Wysocki and C. S. Evans, unpublished results). In mammals, the main olfactory epithelium has diffuse, indirect neural connections to the hypothalamus via the main olfactory bulb and olfactory cortex, whereas the vomeronasal organ has separate and discrete neural connections to the hypothalamus via the accessory olfactory bulb and the amygdala (Scalia and Winans, 1976; Wysocki, 1978; Keverne, 1983). Consequently, by virtue of the neural connections to the hypothalamus of both olfactory epithelia, it is feasible that either, or both, have some influence upon GnRH secretion in the hypothalamus.

The aims of this study were to determine (i) whether ablation of one or both of these olfactory pathways was sufficient to 
reverse the anovulatory state of subordinate female marmoset monkeys while they remained housed with their dominant female and group and (ii) after the anosmia experiments, to examine whether there was a further visual component that might also contribute to the suppression of ovulation in subordinate female marmoset monkeys.

\section{Materials and Methods}

\section{Animals and social group formation}

The animals were captive-born marmoset monkeys raised in the Institute of Zoology, London, under the conditions described by Hearn (1983), with a constant photoperiod of $12 \mathrm{~h}$ light: $12 \mathrm{~h}$ dark. The seven social groups used in this study were formed from unrelated marmoset monkeys; they comprised either offspring taken from large family groups or animals from male-female pairs. All monkeys were post-pubertal (over 15 months of age) as described by Abbott et al. (1988).

Groups were formed by placing 2-4 males and 2-4 females together in an observation room $(2.9 \times 2.2 \times 1.7 \mathrm{~m})$ fitted with interwoven tree branches and a nest box at $1.2 \mathrm{~m}$ above floor level. At 2-4 weeks after group formation, the social groups were housed in home cages $(100 \times 50 \times 75 \mathrm{~cm})$ and attached to an exercise cage $(2 \times 1 \times 2 \mathrm{~m})$ by flexible ducting every $7-10$ days (Hearn et al, 1975).

Two to three days after formation of the group, a dominance hierarchy was established within each sex (Abbott and Hearn, 1978). Behavioural analysis of recorded aggressive and submissive interactions between group members was used to confirm the ranking order, which among the females consisted of a dominant (rank 1) and her subordinates (ranks 2 and below). In summary, the highest ranking female received least aggression and most submissions, whereas the lowest ranking female received most aggression and least submissions (Abbott and Hearn, 1978; Abbott, 1984) Interactions involving feeding and drinking were excluded from the analysis. The rank order within a social group defined reproductive prowess; only the dominant female ovulated. The standardized social groups therefore contained 1-3 reproductively suppressed subordinate females. After removal from the group, and thus the social hierarchy, subordinate females were rapidly capable of ovulating (Abbott, 1984; Abbott et al., 1988).

\section{Blood sampling and assessment of ovarian function}

Blood samples $(0.3 \mathrm{ml})$ were collected from the femoral vein of females every 1-3 days between 09:00 h and 11:00 h (Hearn, 1977) within 5 min of the animal being removed from its cage. The animals remained conscious throughout the procedure and were rewarded with a fruit juice drink and, to help maintain plasma iron concentrations, they were also given $0.3 \mathrm{ml}$ of an iron syrup supplement orally each week (Fersamal, Duncan Flockhart, Greenford). The blood was collected into heparinized syringes and processed as described by Abbott et al. (1981) before hormone assay. The frequency of blood sampling was sufficient to determine ovarian function through the measurement of plasma progesterone concentrations. Dominant female marmosets undergo a 28 day ovarian cycle with a luteal phase lasting about 19-20 days during which plasma progesterone is $>10 \mathrm{ng} \mathrm{ml}^{-1}$ (Harlow et al., 1983). The day of ovulation was taken as the day before the rise of plasma progesterone concentrations to $>10 \mathrm{ng} \mathrm{ml}^{-1}$ : plasma progesterone concentrations remained above $10 \mathrm{ng} \mathrm{ml}^{-1}$ for about 19-20 days. Estimation of the time of ovulation was limited to \pm 1 day.

The luteal phase of a cycle or an early pregnancy was terminated by administering $0.5 \mu \mathrm{g}$ of cloprostenol, a prostaglandin $F_{2 \alpha}$ analogue (Estruamte; ICI, Macclesfield; Summers et al, 1985) by i.m. injection 14-20 days after ovulation, thereby prompting luteolysis and a return to the follicular phase (plasma progesterone $<10 \mathrm{ng} \mathrm{ml}^{-1}$ ) for about 9-13 days.

\section{Progesterone enzymeimmunoassay}

Progesterone concentrations were measured in $5 \mu$ l unextracted plasma using an enzyme-linked immunoabsorbent technique (Hodges et al., 1988), modified from a heterologous enzymeimmunoassay described by Sauer et al. (1986). Each well of a microtitre plate was coated with an anti-progesterone antiserum raised in sheep. Progesterone dissolved in toluene ( $1 \mu \mathrm{g} \mathrm{ml}^{-1}$ ) was dried under nitrogen and reconstituted in PAS-gelatin buffer containing charcoal-treated marmoset plasma $(1: 15 \mathrm{v} / \mathrm{v})$ and serially diluted to produce a range of standards (1.5-200 pg per well). Unextracted plasma samples and quality controls were diluted 1:30 with PAS - gelatin buffer containing charcoaltreated marmoset plasma $(1: 30 \mathrm{v} / \mathrm{v})$. Conjugate, $400 \mu \mathrm{l}$, ( $1: 16000)$ was added to each $100 \mu$ l of standard, sample, quality control and buffer blanks. Duplicate aliquots, $200 \mu \mathrm{l}$, were then removed and placed in the wells of the plate, which was sealed and left at room temperature for $2.5 \mathrm{~h}$ in a humid chamber. Subsequently, each well was rinsed with PAS-gelatin buffer, emptied and replaced with $200 \mu \mathrm{l}$ of substrate ( $p$-nitrophenylphosphate dissolved in diethanolamine buffer). The plates were resealed and incubated in a humid chamber for $1 \mathrm{~h}$ at $37^{\circ} \mathrm{C}$. The

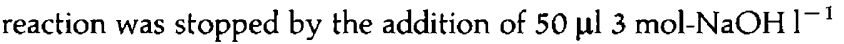
to each well and the optical density was measured at $405 \mathrm{~nm}$ in an automatic plate reader. The standard curve was plotted as percentage bound against known concentrations of standard. A substrate-only well acted as a blank.

The sensitivity of the assay (determined as $90 \%$ binding) was $1.6 \mathrm{ng} \mathrm{ml}^{-1}$ progesterone. The interassay and intra-assay coefficients of variation were $14.3 \%$ and $11.6 \%$, respectively, as determined using high $\left(49.2 \pm 0.7 \mathrm{ng} \mathrm{ml}^{-1}\right.$, mean \pm SEM, $\left.n=20\right)$ and low (10.7 $\pm 0.3 \mathrm{ng} \mathrm{ml}^{-1}, n=20$ ) pools of marmoset plasma.

\section{LH bioassay}

LH was measured in unextracted plasma samples using an in vitro bioassay system using testosterone production from mouse Leydig cells (Harlow et al., 1984; Hodges et al., 1987; Abbott et al., 1988). Unextracted plasma samples (16 $\mu \mathrm{l})$ were assayed in duplicate at 1:50 and 1:100 dilutions. The LH standard used was the 2nd International Reference Preparation of human pituitary gonadotrophin (78/549); triplicate aliquots were taken over the range $6.25-200 \mathrm{iul}^{-1}$. Standards and samples were incubated with $200 \mu \mathrm{l}$ preparation of Leydig 
cells $\left(\mathrm{I} \times 10^{5}\right.$ cells) for $3 \mathrm{~h}$ at $34^{\circ} \mathrm{C}$ in a $95 \% \mathrm{O}_{2}: 5 \% \mathrm{CO}_{2}$ atmosphere. Mice, 5-7-week-old (formerly Tucks No. I strain; outbred at the Institute of Zoology), were used to obtain the Leydig cells.

Radioimmunoassay was used to determine the testosterone production. ${ }^{125}$ I-labelled testosterone (sp. act. $1.7 \times 10^{3} \mathrm{Ci} \mathrm{mmol}^{-1}$ : MRC Reproductive Biology Unit, Edinburgh, UK; Webb et al., 1985 ) and an antiserum raised in sheep against the testosterone3 -carboxymethyloxime conjugate were used. The maximum crossreactivity of the antiserum with other steroids was $12.1 \%$ with dihydrotestosterone, 3.3\% with androsterone and $<1 \%$ with other steroids (Webb et al., 1985). Interassay and intraassay coefficients of variation were $6.2 \%$ and $11.9 \%$, respectively, as determined from marmoset plasma pools $(27.5 \pm 0.4$ and $123.2 \pm 4.3 \mathrm{iu} \mathrm{l}^{-\mathrm{I}}, n=15$ ).

\section{Ablation of the vomeronasal organ}

The monkeys were anaesthetized by i.m. injection of Saffan (24 $\mathrm{mg} \mathrm{kg}^{-1}$; Pitman-Moore, Harefield). A custom-built frame with earbars and adjustable jaw retractors was used to restrain the unconscious animal in a supine position. Hand-held calipers were used to determine the anterior and posterior points of the vomeronasal organ (VNO) relative to the rostral side of the upper incisors (5.4 $\mathrm{mm}$ and $9.4 \mathrm{~mm}$, respectively), using coordinates previously determined from heads obtained post-mortem.

A diathermic cutting tool was used to remove the soft tissue protecting the hard palate to reveal about $4 \mathrm{~mm}^{2}$ of bone. Two small, distinct holes were drilled into the hard palate on either side of the nasal septum using a fine bore (1.1 $\mathrm{mm}$ diameter) hand-held drill so that the centres of the holes lay $1 \mathrm{~mm}$ apart across the nasal septal midline. Drilling through the hard palate exposed the anterior bilateral portions of the vomeronasal organ. A diathermic cutting tool was then inserted to cauterize the posterior part of the nasopalatine canal and the majority of the vomeronasal organ. Glass ionomer luting cement (Aquacem; Dentsply Ltd, Weybridge) was used to seal the incision site. The animals were then allowed to recover fully from the anaesthetic and were given i.m. injections of antibiotic $(0.1 \mathrm{ml}$ Clamoxyl LA; Beecham Animal Health, Brentford, Middlesex) and an analgesic before being returned to their social groups. Histological examination of the vomeronasal region was performed to confirm the extent of the lesions. For behavioural trials only, sham lesion controls underwent the same procedures, but a small portion of the lower palate was cauterized thereby ensuring the vomeronasal organ was unaffected.

\section{Ablation of the main olfactory epithelium}

The monkeys were anesthetized by i.m. injection of ketamine hydrochloride (12.5 $\mathrm{mg} \mathrm{kg}^{-1}$; Vetalar, Parke Davis, Pontypool). The animals were then held horizontally in lateral recumbency and a fine bore polyvinyl catheter (external diameter $0.61 \mathrm{~mm}$, Portex Ltd, Hythe) was inserted $10 \mathrm{~mm}$ into the nasal cavity via the external nares. At this depth the catheter penetrated to the region of the main olfactory epithelium, as previously determined from the histological examination of post-mortem specimens. The catheter was attached to a $1 \mathrm{ml}$ syringe containing $0.2 \mathrm{ml}$ of $5 \%$ zinc sulfate solution $(\mathrm{w} / \mathrm{v})$ in distilled water.
When the catheter was in place, $0.1 \mathrm{ml}$ of the zinc sulfate solution was administered while the animal was slowly turned so that it was held inverted. A further $0.1 \mathrm{ml}$ was administered while the catheter was being withdrawn. Subsequently, excess zinc sulfate solution was removed by douching with saline. The animals remained in the inverted position for $2 \mathrm{~min}$ and the process was then repeated on the other nasal cavity to prevent lung congestion from the infusion of liquid. The animals were allowed to recover fully before being returned to their social groups. The administration of zinc sulfate solution was repeated every 1-3 weeks. This regimen was adopted to prevent any return of function to the main olfactory epithelium, as in rhesus monkeys, following ablation of the main olfactory epithelium with a single nasal irrigation of $1 \%$ zinc sulfate solution, regeneration of the main olfactory epithelium began 10-20 days after treatment, although it was not completed for several months (Schultz, 1960). For the behavioural trials only, sham controls were treated in a similar manner except that the catheter was placed at the entrance to the external nares and no solution was administered into the nasal cavity, thereby avoiding possible damage to the delicate olfactory epithelium of control animals. The extent of the lesions was confirmed by histological examination.

\section{Histology}

After the olfactory ablation experiments, each marmoset monkey was killed with an i.m. injection of Saffan ( $30 \mathrm{mg} \mathrm{kg}^{-1}$ ) following by an i.v. injection of Euthatal ( $1 \mathrm{~g} \mathrm{~kg}^{-1}$; pentobarbitone sodium, Mary and Baker Ltd, Dagenham). Heads were placed in neutral buffered $10 \%$ formalin for two weeks. Subsequently each head was placed in $8 \%$ formic acid to decalcify. The time taken for complete decalcification ranged from 8 to 12 weeks. Once decalcified, the heads were dehydrated through a series of alcohols to absolute alcohol and finally embedded in paraffin wax. Once embedded, coronal sections were cut between $6-8 \mu \mathrm{m}$ thick and stained with haemotoxylin and eosin.

\section{Experimental design}

Anosmia phase. Only subordinate females that had been anovulatory in social groups for at least 8 weeks were used in this study. Initially, three subordinate females underwent ablation of the vomeronasal organ and four subordinates underwent ablation of the main olfactory epithelium. All seven subordinate females were maintained in their social groups for 7 weeks before five of the original seven animals had received a second lesion, thus making these five animals anosmic at both the main olfactory epithelium and the vomeronasal organ. The five double-lesioned animals were returned to their social groups for a further 7 weeks.

Visual phase. After the olfactory-lesion experiment, five double and one single olfactory-lesioned (at the main olfactory epithelium) subordinate female were maintained with their groups and were rehoused in cages $(104 \times 66 \times 91 \mathrm{~cm})$ that had been divided equally by a transparent perspex divider. Each half of the cage contained a transparent perspex nest-box 
$(28 \times 31 \times 18 \mathrm{~cm})$ and three wooden perches. Each lesioned subordinate female was physically separated from her dominant female and the rest of her group on one side of the perspex division. Visual, but not physical, access was therefore available at all times between the isolated subordinate female and her dominant female and group. The six lesioned subordinate females were maintained in visual-contact-only for 7 weeks.

Throughout these experiments, plasma concentrations of $\mathrm{LH}$ and progesterone were determined in all subordinate females to assess whether the olfactory lesions or the visual access only experiment resulted in increased plasma $\mathrm{LH}$ concentrations and the onset of ovulation.

At the end of the visual-contact-only phase, five of the original six groups were studied for $30 \mathrm{~min}$ from behind a oneway mirror: (i) while the perspex divider was still in place; and (ii) immediately after the removal of the perspex divider. Only the behavioural interactions between the dominant female and the previously separated subordinate female were recorded. Behaviour recorded was (i) aggression, consisting of vocal threats and physical attacks, (ii) submission, consisting of submissive vocalizations and facial grimaces, and (iii) bristle strut, pilo-erection of the fur accompanied by a pronounced and deliberate movement with arched back (for details see Stevenson and Poole, 1976; Abbott and Hearn, 1978; Abbott, 1984). The aggressive and submissive interactions between the females determined their dominant and subordinate status.

\section{Scent discrimination trials}

Male and female scent. Scent trials were performed with six singly housed males to determine whether the zinc sulfate lesion of the main olfactory epithelium rendered marmoset monkeys effectively anosmic. Each male was presented with two aluminium discs of $8.4 \mathrm{~cm}$ diameter, each thoroughly cleansed in detergent overnight, rinsed in distilled water, then in absolute alcohol and finally air dried. Similar discs were placed in the cages of dominant cycling females either housed singly or in all female groups. Discs were maintained on the cages of males to be tested and of the donor females for 1-4 days to collect scent marks. During this time the discs were also marked by the animals with urine and faeces.

Immediately before a scent trial, the male to be tested was removed from his home cage along with the nest-box, water bottle and food. One disc from the male's own home cage and one disc from a donor female's cage were placed on the male's home cage on a horizontal plane about $20-25 \mathrm{~cm}$ apart. An effect of side preference was countered by randomly positioning each disc on either side of the cage. Clean, disposable gloves were worn by observers at all times. When the discs were in place, the male was returned to his home cage for a $15 \mathrm{~min}$ behaviour trial. During each trial, an observer sat behind a one-way mirror and scored behaviour directed at a disc by the male. Behaviour scored was - on: the male touched or sat on the disc; sniff: the male sniffed the disc; lick: the male licked the disc; rub: the male rubbed the disc with his face, chest or arms; and scentmark: the male exhibited circumgenital scent marking of the disc. Trials were performed at least once a week for 3-4 weeks before the male received either zinc sulfate ablation of the main olfactory epithelium $(n=3)$ or the sham procedure
( $n=3$, controls) and were continued for a further 7 weeks following the lesion or sham procedure. At the end of the experiment, the males were killed and histological examination was performed to confirm the extent of the lesions.

\section{Olfactory repugnance trials}

The behaviour trials outlined above were supplemented by performing a series of olfactory repugnance tests to determine whether ablation of the main olfactory epithelium or the vomeronasal organ affected the ability of the marmoset to detect a repugnant smell. The evening before the trial the marmoset was singly housed in its home cage and all food was removed. Immediately before the trial, the marmoset was removed from its home cage along with its nest-box and water bottle. Two perspex boxes $(52 \times 52 \times 35 \mathrm{~mm})$ were fitted to the front of the cage about $15-20 \mathrm{~cm}$ apart. The perspex lids of the boxes were perforated to allow the animal olfactory and visual access, without physical contact, to the contents of the box. Inside each box was 3-4 half slices of banana and in one box only, the banana was covered with $1-2 \mathrm{ml}$ of $1 \%$ caproic acid solution (this produces a goat-like smell repugnant to marmosets: A. F. Dixson, personal communication). The animal was returned to its home cage for a $10 \mathrm{~min}$ behavioural trial. The observer sat behind a one-way mirror and only scored behaviour directed at the perspex boxes. Behaviour scored was - on: the marmoset sat on the box; sniff: the marmoset sniffed either the side or the lid of the box; lick: the marmoset licked either the top or the side of the box; head shake: after sniffing the box the marmoset shook its head; sneezing: after sniffing the box the marmoset sneezed; retreat: after sniffing the box the marmoset immediately and rapidly withdrew to the back of the cage; and investigate: the marmoset manually attempted to remove the lid of the box or to push its fingers through the holes in the box lid to reach the contents of the box. Six intact marmosets, six marmosets sham-lesioned at both the vomeronasal organ and main olfactory epithelium, seven marmosets lesioned at the vomeronasal organ, six marmosets lesioned at the main olfactory epithelium and seven marmosets lesioned at both the vomeronasal organ and the main olfactory epithelium were tested for anosmia using this olfactory repugnance test.

\section{Statistical analysis}

The data were submitted to the appropriate analysis of variance (ANOVA), with or without a repeated measures design (Statistical Analysis System [SAS]; Helwig and Council, 1979). Log transformation of plasma LH concentrations and of behaviour scores (with the addition of one to each score to compensate for any zero values) was carried out to increase the linearity of the data and to reduce the heterogeneity of variance. This is a standard method for improving the quality of the data before carrying out an analysis of variance of the least squares method (Helwig and Council, 1979; Sokal and Rohlf, 1981). In all cases, comparisons of individual transformed means were made post hoc using Duncan's Multiple Range test (Helwig and Council, 1979). 
(a)

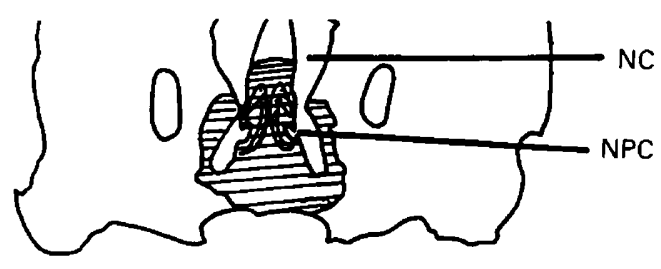

(b)

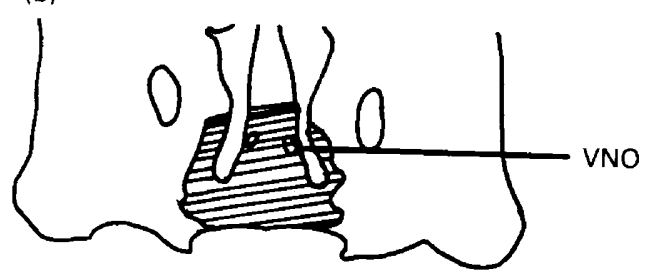

(c)

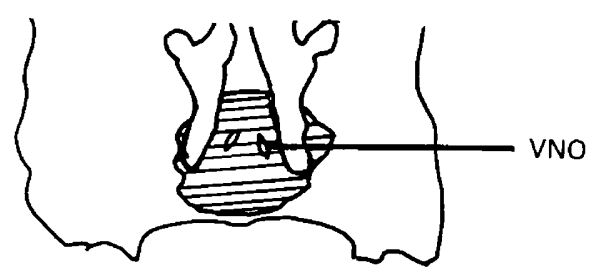

Fig. 1. Photomicrograph drawings of the coronal sections through the head of an intact marmoset monkey. Shaded area demonstrates the extent of the lesioning to the vomeronasal organ (VNO) in one female (No. $361 \mathrm{~W}$ ) in which complete ablation of the VNO occurred. In (a) the nasopalatine canal (NPC), is shown opening into the nasal cavity $(\mathrm{NC})$; (b) shows the anterior portion of the $\mathrm{VNO}$ at about $1.3 \mathrm{~mm}$ along its length; and (c) demonstrates the VNO at about $3 \mathrm{~mm}$ from its anterior point.

\section{Results}

\section{Histological verification of olfactory lesions}

Histological examination revealed complete ablation of the vomeronasal organ in four of the five double-lesioned subordinate females (Fig. 1a, c). In one subordinate female the majority of the vomeronasal organ was ablated resulting in the obstruction of the nasopalatine canal and the isolation of $2.4 \mathrm{~mm}$ of the caudal portion of the vomeronasal organ (Fig. Ia, b) which, dissected out of intact animals, measured $4.08 \pm 0.26 \mathrm{~mm}$ (mean $\pm \mathrm{SEM}, n=5$ ). Thus, in all five subordinate females, the ablation technique was successful in blocking olfactory access to the olfactory epithelium of the vomeronasal organ (see Fig. 2).

Histological examination of the olfactory epithelium of intact marmoset monkeys $(n=3)$ revealed that the olfactory epithelium was approximately $45 \mu \mathrm{m}$ thick and consisted of a compact arrangement of cells: basal cells lay at the base of the epithelial layer close to the lamina propria and olfactory cells and columnar supporting cells lay above the basal cells. No differential staining was performed to distinguish between supporting cells and olfactory cells. This pseudostratified layer appeared to lie directly on the lamina propria, which contains the Bowman's glands responsible for producing a serous secretion found on the surface of the olfactory epithelium. The coronal sections from intact marmosets (Fig. 3a) contrasted with coronal sections from zinc sulfate-treated marmoset monkeys $(n=6)$ in which the pseudostratified layer of the olfactory epithelium was approximately $25 \mu \mathrm{m}$ thick, appeared to have fewer nuclei throughout the epithelium, was disorganized (lacking the compact arrangement of olfactory and supporting cells seen in the control sections), and was detached from the lamina propria (Fig. 3b). This histology is typical of zinc sulfate treatment, as seen in Rhesus monkeys treated with a $1 \%$ zinc sulfate solution (Schultz, 1960), and suggests an impairment of olfactory function.

\section{Scent discrimination trials}

Male and female scent. Owing to a significant interaction $(F[1,2]=4.75, P<0.05)$ between olfactory treatments and test perches, one-way analyses of variance (ANOVA) were used to determine the effects of treatment on sniffing behaviour. Males showed a significant preference for sniffing at the disc from a female's cage as opposed to their own disc, when either pre-sham lesion $(F[1,4]=75.5, P<0.001)$, post-sham lesion $(F[1,4]=9.92, P<0.05)$ or pre-zinc sulfate lesion $(F[1,4]=11.7$, $P<0.05$ : Fig. 4). Males treated with zinc sulfate did not show any preference thereby illustrating the efficacy of the zinc sulfate treatment to induce long-term anosmia.

Licking was directed significantly more at the perches from females' cages when all treatment groups $(F[1,8]=14.3$, $P<0.006)$ were combined. However, males treated with zinc sulfate did not lick either perch. There were no significant differences in on, rub or scentmark behaviours directed at male or female perches among the different treatment groups.

\section{Olfactory repugnance trials}

Licking behaviour was unaffected by treatment as the boxes containing banana alone were licked significantly more than those containing banana and caproic acid, regardless of treatment $(F[1,1]=8.95, P<0.01)$. Similarly, regardless of treatment, animals shook their heads after sniffing at the box containing banana and caproic acid more than at the box with banana alone $(F[1,1]=8.04, P<0.01)$.

As a result of an interaction found for retreat and investigate behaviours, one-way ANOVA was performed to determine the effects of treatment upon these behaviours. Only animals with intact main olfactory epithelium retreated from the caproic acid $(F[4,27]=10.53, P<0.0001)$, strongly suggesting that main olfactory epithelium ablations rendered female marmosets unresponsive to the caproic acid odour and anosmic. ANOVA revealed no consistent trend in investigative behaviour for main olfactory epithelium intact treatments (intact controls, sham controls and single vomeronasal organ lesion) versus main olfactory epithelium lesioned treatments (main olfactory epithelium single lesion and double lesions).

\section{Hormone profiles}

Anosmia phase. After (i) ablation of the vomeronasal organ ( $n=3$, e.g. Fig. 3a), (ii) ablation of the main olfactory 

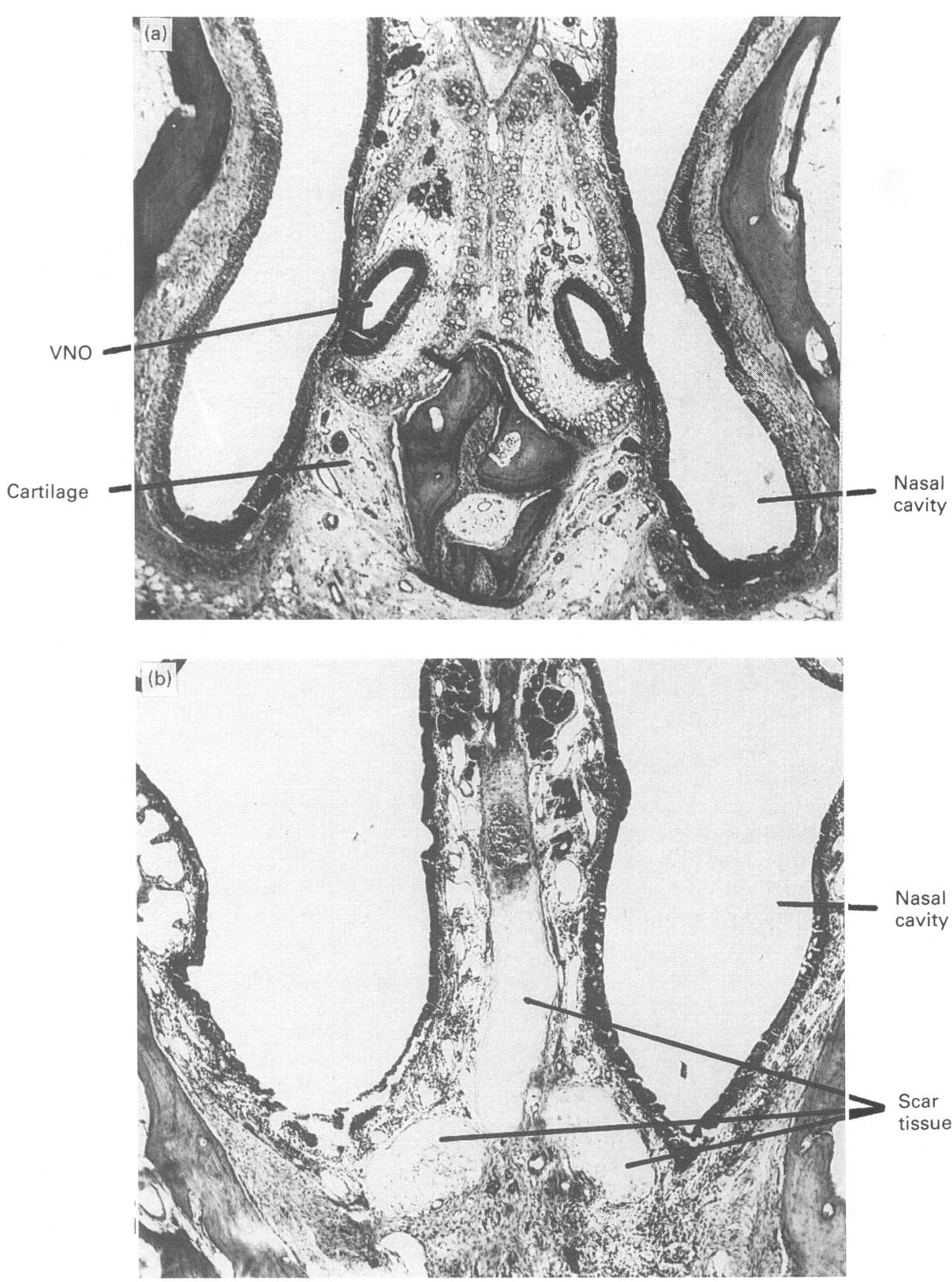

Fig. 2. Equivalent coronal sections through the heads of two marmosets showing the presence of the vomeronasal organ (VNO) at about $1.3 \mathrm{~mm}$ along its length, (a) in the intact animal $(\times 40)$ and (b) the absence of the VNO and resulting scar tissue in a lesioned animal $(\times 40)$ where the VNO was completely ablated.

epithelium ( $n=4$, e.g. Fig. 3 b) or (iii) ablation of both the vomeronasal organ and the main olfactory epithelium $(n=5$, e.g. Fig. 3c), none of the subordinate females showed any reversal of their anovulatory state while they were maintained with their dominant female and her group, illustrated (Fig. 5) by the continued low, acyclic concentrations of progesterone $\left(<10 \mathrm{ng} \mathrm{ml}^{-1}\right)$ of the subordinates. Plasma LH concentrations measured across control (2.62 (2.17-3.17) iu $\mathrm{l}^{-1}$, anti-log of the transformed mean and $95 \%$ confidence limits) and lesion phases ((1) 3.03 [1.88-4.86] iu $1^{-1}$ (2) 5.3 [3.06-9.19] iu $1^{-1}$, (3) $\left.2.86[2.23-3.67] \mathrm{iu}^{-1}\right)$ remained low and acyclic and there was no significant difference in LH values between control and lesion phases $((1) F[11,22]=0.13, P>0.09$, (2) $F[11,36]=1.63$, $P>0.1,(3) F[11,48]=1.34, P>0.2$ ).

Three dominant females that were lesioned at both the main olfactory epithelium and vomeronasal organ continued to ovulate and, after the second lesion, they had a follicular phase of $6.6 \pm 0.66$ days (mean \pm SEM) and a subsequent luteal 
(a)

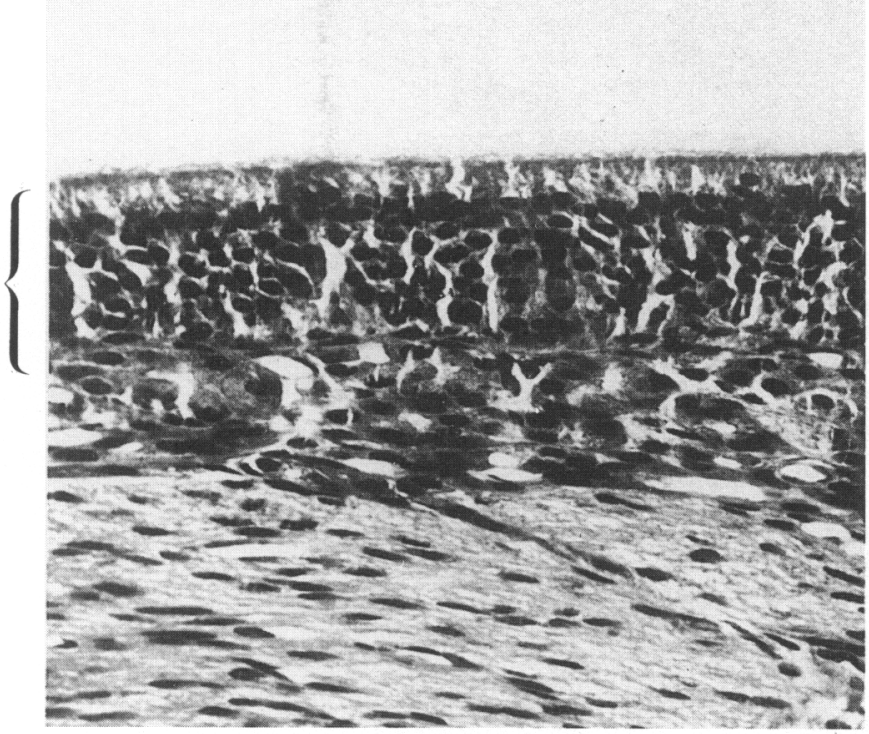

(b)

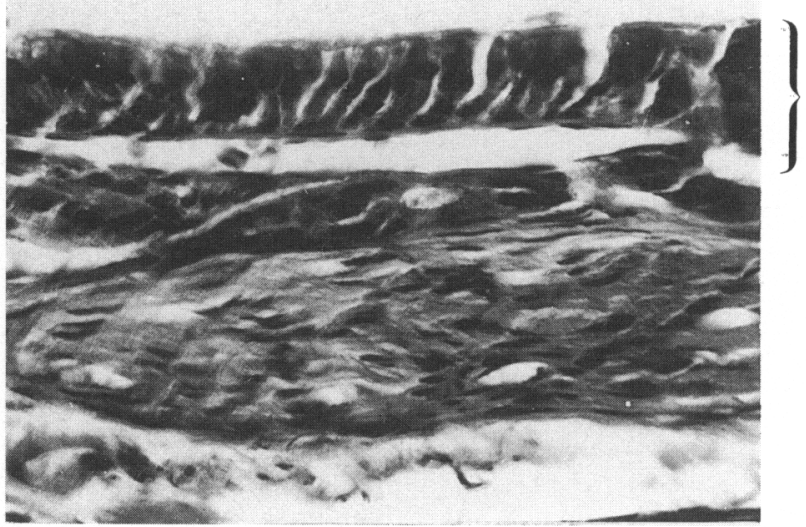

Fig. 3. Equivalent coronal sections $(\times 100)$ through the olfactory epithelium of (a) a control marmoset monkey and (b) a female 7 months after the start of treatment with zinc sulfate. The brackets positioned alongside the figures indicate the relative thickness of each layer. The epithelial layer is regular and compact in the control animal (a) but is more disorganized in animals treated with zinc sulfate (b) and in some places along the section was detached from the lamina propria (b).

phase of $21.3 \pm 1.2$ days, which is compatible with intact, dominant females.

Plasma LH concentrations were significantly higher (ANOVA, $F[4,4]=7.07, P<0.05)$ during the visual-contact-only period compared with control, both single vomeronasal and single main olfactory epithelium lesion, and double-olfactory lesioned animals remaining in their groups.

\section{Visual phase}

During the 7 weeks of visual-contact-only in which the six lesioned subordinate females were separated from their dominant female and group by a transparent perspex partition, the time to the onset of first ovulation in subordinate females was $29.1 \pm 9.3$ days. This was significantly delayed $(F[1,12]=5.1, P<0.05)$ compared with the time taken for subordinate females completely isolated from their dominant females to ovulate $(n=8,10.8 \pm 1.3$ days; Barrett et al., 1990). Of the three anosmic subordinate female marmosets that ovulated and completed an ovarian cycle within the 7 weeks of the visual-only experiment, their luteal phases lasted 20, 23 and 17 days, respectively, and were apparently of normal duration in comparison to those seen in intact cycling females of approximately 19-20 days (Harlow et al., 1983). This is exemplified by female $335 \mathrm{~W}$ (Fig. 6) which ovulated at day 8 of the visual-only contact phase, had a luteal phase of 23 days, and reovulated on day 39 . The three remaining lesioned subordinate females did not ovulate.

After the 7-week visual-contact-only experiment, five of the six lesioned subordinate females were returned to their dominant females and groups. Of these five, only two subordinate females had ovulated in the previous 7 weeks. Dominant females showed aggressive behaviour towards the returning subordinate in two of the five groups: only one of these subordinates had ovulated during the 7 week visual-contact-only experiment. In the remaining three groups, the dominant female did not show aggressive behaviour towards the returning subordinate: this included the remaining subordinate that had ovulated during the 7 week visual-contact-only experiment. Returning ovulatory subordinate females into their original social groups did not therefore appear to generate a reliable aggressive response from their dominant female.

Three returning subordinate females displayed submissive behaviour to their dominant female: one of these subordinates was, and two of these subordinates were not, treated aggressively by their dominant female. All dominant female marmoset monkeys displayed bristle strut behaviour (typical of dominant female marmosets) when their lesioned subordinate female was returned while, significantly, only one returning subordinate female showed this behaviour $(P<0.05$, Fisher's exact probability test; Siegel, 1956). This latter female was one of the two subordinates that had ovulated while in the visual-contactonly phase, but this female was not treated aggressively by her dominant female on return to the group. Taken together, these behavioural results suggest that the previous dominant and subordinate status of females remained unchanged following the 7 week visual-contact-only experiment.

\section{Discussion}

These results show that ablation of the vomeronasal organ or the main olfactory epithelium, or both, is insufficient to reverse the anovulatory state of long-term subordinate female marmoset monkeys while they were housed with their dominant female and social group. These findings contrast with those 
(a)

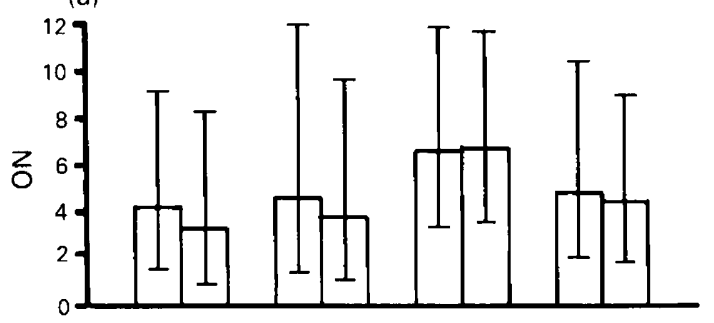

(b)
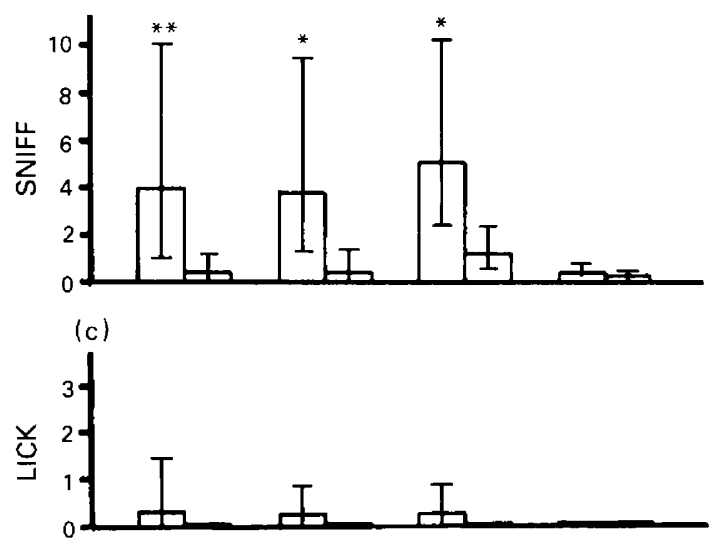

(d)

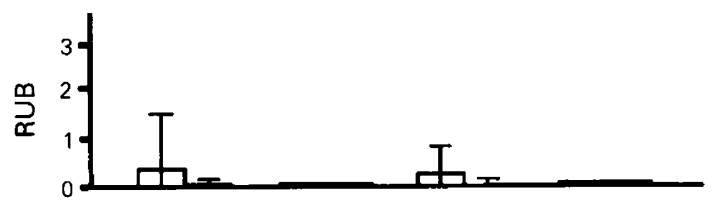

(e)

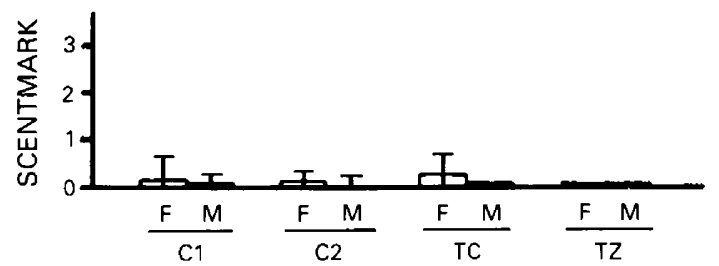

Fig. 4. Frequency of behaviour (antilog of transformed means $\pm 95 \%$ confidence limits) exhibited by male marmosets $(n=6)$, (a) on, (b) sniff, (c) lick, (d) rub or (e) scentmark behaviour directed at the perches donated by a female $(F)$ or the male himself $(M)$. Treatment categories are $\mathrm{C} 1$, pre-sham lesion $(n=3)$; C2, pre-zinc-sulfate lesion $(n=3)$; $\mathrm{TC}$, post-sham lesion $(n=3)$; and TZ, post-zinc-sulfate lesion $(n=3)$. ${ }^{*} P<0.05,{ }^{* *} P<0.001$, male-donated versus female-donated perches.

obtained following scent transfer (Barrett et al., 1990) in which scent alone from the dominant female marmoset was shown to play a role in maintaining reproductive suppression in subordinate females. On the basis of both our present and previous work, it would seem that although chemical signals from the dominant female marmoset do play a part in maintaining the suppression of ovulation in subordinate females, they may not be the major factor in the maintenance of this reproductive suppression. Since ablation of the vomeronasal organ and the main olfactory epithelium prevented the anosmic group-housed subordinates from perceiving olfactory stimuli from their dominant female, some other social cue, such as visual, behavioural or tactile, from the dominant female may play the major (a) $430 \mathrm{~W}$

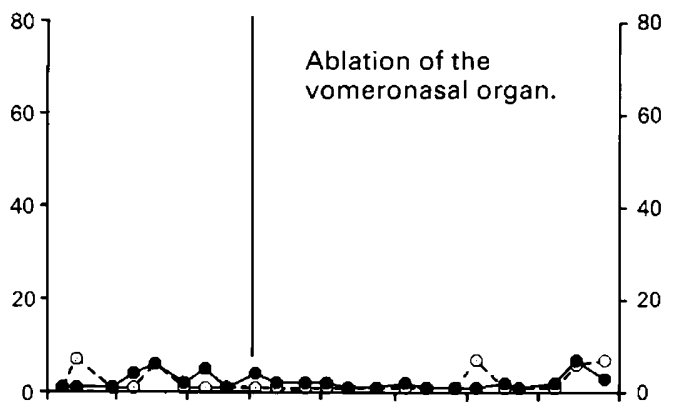

(b) $361 \mathrm{~W}$

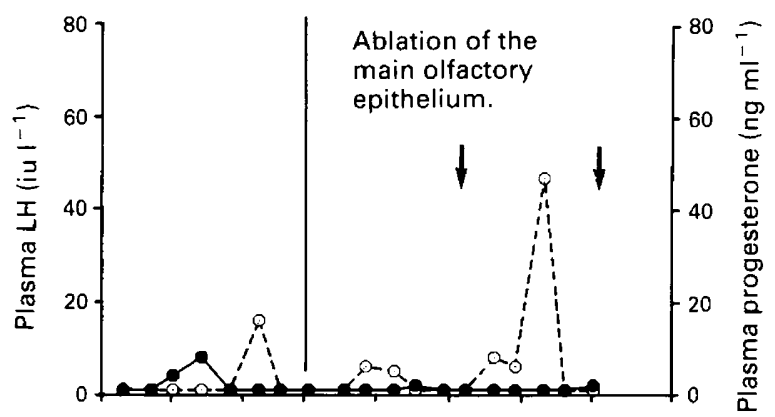

(c) $432 \mathrm{~W}$

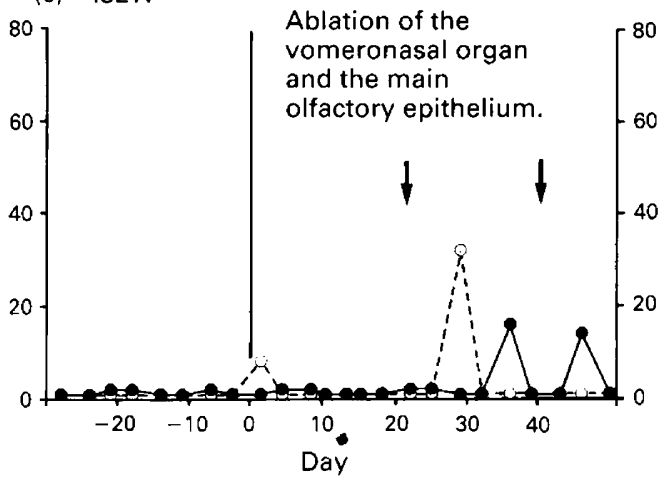

Fig. 5. Profiles of luteinizing hormone $(\mathrm{LH})(\bigcirc)$ and progesterone ( in three typical subordinate females that underwent (a) a pre-lesion phase followed by ablation of the vomeronasal organ, (b) a pre-lesion phase followed by ablation of the main olfactory epithelium, repeated every 3 weeks (as indicated by arrows), with $5 \%$ zinc sulfate solution, or (c) a second lesion, so that the females were ablated at the vomeronasal organ and the main olfactory epithelium. All lesioned subordinate females remained housed with their dominant female and group throughout pre-, single and double lesion phases.

role in maintaining the anovulatory state of subordinate female marmosets. Auditory cues do not play a role in maintaining this reproductive suppression (Barrett et al., 1990).

In this respect, this paper has also shown that visual cues from the dominant female do play a role in maintaining the suppression of ovulation in subordinate females. The onset of ovulation in the olfactory-lesioned subordinate females kept in visual-contact-only with their dominant female (approximately 29 days) was similarly delayed in the subordinate females kept only in scent contact with their dominant females (approximately 32 days; Barrett et al., 1990). Both groups of isolated subordinate females took longer to ovulate than isolated 


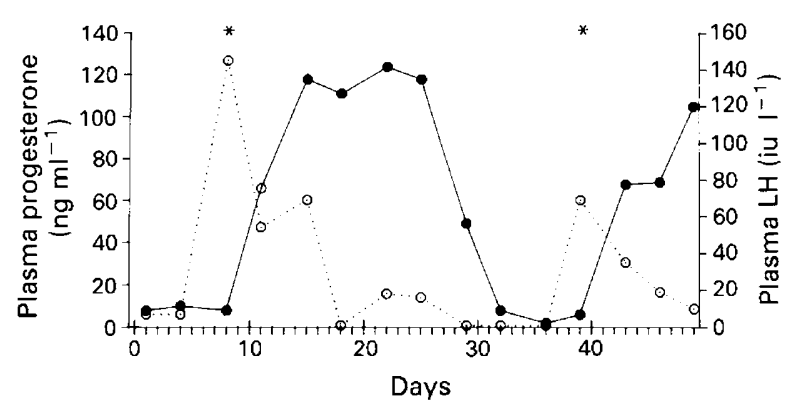

Fig. 6. Profile of luteinizing hormone (LH) (०) and progesterone (•) in one of three ovulatory double olfactory-lesioned subordinate females, maintained in visual-contact-only with her dominant female and group. Ovulation times following the initiation of the visualcontact-only phase are indicated by ${ }^{*}$ on day 8 and day 39 , respectively. Three double olfactory-lesioned subordinate females did not ovulate during this period.

subordinate controls, which ovulated after approximately 11 days. These results also suggest that behavioural or tactile cues from the dominant female may play an important part in this reproductive suppression because (i) neither olfactory nor visual cues alone could maintain complete suppression of ovulation and (ii) olfactory lesioned subordinates remaining in their groups maintained their suppressed plasma LH concentrations and anovulatory status. There may therefore be separate olfactory, visual and behavioural or tactile components involved in the maintenance of suppressed ovulation in subordinate female marmosets by their dominant females.

Previous work has also suggested that although pheromonal cues may play a role in maintaining reproductive suppression in subordinate female marmosets, they may not be the only important inhibitory factor, e.g. the common marmoset (Barrett et al., 1990) and its close relatives, the saddle-back tamarin, Saguinus fuscicollis (Epple and Katz, 1984) and cotton-top tamarin S. oedipus (Savage et al., 1988). However, a direct pheromonal suppression of reproduction has been identified in the subordinate male lesser mouse lemur, Microcebus murinus (Schilling et al., 1984; Schilling and Perret, 1987) and in the juvenile female white-footed mouse, Peromyscus leucopus (Haigh et al., 1988). The range of cues that may maintain reproductive suppression in subordinate female marmosets may reflect the enlargement of the primate neocortex. In other mammals, pheromonal cues have been shown to act synergistically with other cues to alter reproductive physiology, such as tactile cues in the induction of early puberty in female mice (Bronson and Maruniak, 1975) or visual and behavioural cues in the raminduced secretion of $\mathrm{LH}$ in anoestrous ewes (Cohen-Tannoudji et al., 1986).

The effectiveness of visual cues alone (present study) or olfactory cues alone (Barrett et al., 1990) from dominant females in extending the suppression of ovulation in their isolated subordinate females suggests that there might be some degree of recognition on the part of the subordinate females, of the dominant's visual image or olfactory profile. However, whether this is recognition by the subordinate female of her own dominant female's visual and olfactory cues or whether it is recognition of visual and olfactory cues that are common to all dominant female marmosets remains to be established.
Present studies involving naive anosmic females have suggested olfactory cues play an essential role in the initiation of reproductive suppression of subordinate females during early group formation.

In the pregnancy block effect (the Bruce effect; Bruce, 1959) induced in female mice by a male unfamiliar to the female, Keverne and colleagues (Keverne and de la Riva, 1982; Keverne, 1983, 1990; Lloyd-Thomas and Keverne, 1982) have clearly shown that recognition of the olfactory profile of the mating male, obtained via the vomeronasal organ and the accessory olfactory bulb, is crucial for the fertility block imposed by an unfamiliar male to occur. No particular chemical appears important.

There can be no doubt about the completeness of the olfactory ablations in the present study, because of the histological verification of the destruction of both olfactory epithelia and, for the main olfactory epithelia alone, because of the complete loss of behavioural discrimination between male and female marmoset scents and between an innocuous and a repugnant smell. The ability of marmosets with only vomeronasal organ ablations to discriminate between innocuous and repugnant smells suggested that the main olfactory epithelium remained intact in these animals and that each ablation procedure was discrete. The anosmic procedures carried out on marmosets in this study did not have any effect, per se, on ovulation because three out of six lesioned subordinate females ovulated during the visualcontact-only procedure and because all three double-lesioned dominant females showed no interruption to their regular pattern of ovulatory cycles. Similar olfactory ablations have also had no inhibitory effects on ovulation in female mice (Lloyd-Thomas and Keverne, 1982).

Our thanks go to A. P. F. Flint and H. M. Moore for criticism of the manuscript, M. J. Llovet and his animal staff for care and maintenance of the marmosets, G. F. Nevill and W. G. Ray for design and construction of technical equipment, T. J. Dennett and M. J. Walton for preparation of the figures, plates and tables and L. Forbes and $\mathrm{A}$. McCormick for typing the manuscript. This work was supported by a grant from the Wellcome Trust.

\section{References}

Abbott DH (1984) Behavioral and physiological suppression of fertility in subordinate marmoset monkeys American journal of Primatology 6 169-186

Abbott DH (1988) Natural suppression of fertility Symposium of Zoological Society of London $607-28$

Abbott DH (1989) Social suppression of reproduction in primates. In Comparative Socioecology. The Behavioural Ecology of Humans and Other Mammals, pp 285-304 (Symposium No. 8 of The British Ecological Society) Eds V Standen and RA Foley. Blackwell Scientific Publications, Oxford

Abbott DH and Hearn JP (1978) Physical hormonal and behavioural aspects of sexual development in the marmoset monkey, Callithrix jacchus Joumal of Reproduction and Fertility 53 155-166

Abbott DH, McNeilly AS, Lunn SF, Hulme MJ and Burden FJ (1981) Inhibition of ovarian function in subordinate female marmoset monkeys (Callithrix jacchus jacchus) Journal of Reproduction and Fertility 63, 335-345

Abbott DH, Hodges JK and George LM (1988) Social status controls LH secretion and ovulation in female marmoset monkeys (Callithrix jacchus) Journal of Endocrinology 117 329-339

Barrett J, Abbott DH and George LM (1990) Extension of reproductive suppression by pheromonal cues in subordinate female marmoset monkeys, Callithrix jacchus Joumal of Reproduction and Fertility $90411-418$

Beattie J (1927) The anatomy of the common marmoset Proceedings of the Zoological Society of London 97 (Part 3), 593-718 
Bronson FH and Maruniak JA (1975) Male-induced puberty in female mice: evidence for a synergistic action of social cues Biology of Reproduction 13 94-98

Bruce HM (1959) An exteroceptive block to pregnancy in the mouse Nature 184105

Cohen-Tannoudji J, Locatelli A and Signoret JP (1986) Non-pheromonal stimulation by the male of LH release in the anoestrous ewe Physiology and Behavior 36 921-924

Epple G and Katz Y (1984) Social influences on estrogen excretion of ovarian cyclicity in Saddle-back tamarins (Saguinus fuscicollis) American Joumal of Primatology 6 215-227

Haigh GR, Cushing BS and Bronson FH (1988) A novel postcopulatory block of reproduction in white-footed mice Biology of Reproduction 38 623-626

Harlow CR, Gems S, Hodges JK and Hearn JP (1983) The relationship between plasma progesterone and the timing of ovulation and early embryonic development in the marmoset monkey (Callithrix jacchus) Journal of Zoology 201 273-282

Harlow CR, Hearn JP and Hodges JK (1984) Ovulation in the marmoset monkey: endocrinology, prediction and detection Joumal of Endocrinology 103 17-24

Harrison D (1987) Preliminary thoughts on the incidence, structure and function of the mammalian vomeronasal organ Acta Otolaryngologica Stockholm 103 489-495

Hearn JP (1977) The endocrinology of reproduction in the common marmoset, Callithrix jacchus In The Biology and Conservation of the Callitrichidae, pp 163-171 Ed. DG Kleiman, Smithsonian, Washington

Hearn JP (1983) The common marmoset (Callithrix jacchus). In Reproduction in New World Primates, pp 161-215 Ed. JP Hearn. M.T.P. Press, Lancaster

Hearn JP, Lunn SF, Burden FJ and Pilcher MM (1975) Management of animals for biomedical research Laboratory Animals 9 125-134

Helwig JT and Council KA (1979) SAS User's Guide. SAS Institute Inc., Cary

Hodges JK, Cottingham PG, Summers PM and Yingnan L (1987) Controlled ovulation in the marmoset monkey (Callithrix jacchus) with human chorionic gonadotrophin following prostaglandin-induced luteal regression Fertility and Sterility 48 299-305

Hodges JK, Green DI, Cottingham PG, Sauer MJ, Edwards C and Lightman SL (1988) Induction of luteal regression in the marmoset monkey (Callithrix jacchus) by a gonadotrophin-releasing hormone antagonist and the effects on subsequent follicular development. Journal of Reproduction and Fertility $\mathbf{8 2}$ $743-752$

Hubrecht RC (1984) Field observations on group size and composition of the common marmoset (Callithrix jacchus jacchus), at Tapacura, Brazil Primates $\mathbf{2 5}$ 13-21

Keverne EB (1983) Pheromonal influence on the endocrine regulation of reproduction Trends in the Neurosciences 6 381-384

Keverne EB and de la Riva C (1982) Pheromones in mice: reciprocal interaction between the nose and brain Nature 296 148-150
Lloyd-Thomas A and Keverne EB (1982) Role of the brain and accessory olfactory system in the block to pregnancy in mice Neuroscience 7 907-913

Sauer MJ, Foulkes JA, Worsfold A and Morris BA (1986) Use of progesterone I1-glucuronide-alkaline phosphatase conjugate in a sensitive microtitreplate enzymeimmunoassay of progesterone in milk and its application to pregnancy testing in dairy cattle Journal of Reproduction and Fertility 76 375-391

Savage A, Ziegler TE and Snowdon CT (1988) Sociosexual development, pair bond formation, and mechanisms of fertility suppression in female CottonTop Tamarins (Saguinus oedipus oedipus) American Joumal of Primatology 14, 345-359

Scalia F and Winans SS (1976) New perspectives on the morphology of the olfactory system: olfactory and vomeronasal pathways in mammals. In Mammalian Olfaction, Reproductive Processes and Behavior, pp 7-28 Ed. RL Doty. Academic Press, New York

Schilling A and Perret M (1987) Chemical signals and reproductive capacity in a male prosimian primate (Microcebus murinus) Chemical Senses 12 143-158

Schilling A, Perrett M and Predine J (1984) Sexual inhibition in a prosimian primate: a pheromone-like effect Journal of Endocrinology 102 143-151

Schultz EW (1960) Repair of the olfactory mucosa American Joumal of Pathology $371-19$

Siegel S (1956) Non-parametric Statistics for the Behavioral Sciences. McGraw-Hill Koger Kushe, Tokyo

Sokal RR and Rohlf FJ (1981) Biometry: The Principles and Practice in Biological Research (2nd Edn) W. H. Freeman \& Co., New York

Stevenson MF (1978) The behaviour and ecology of the common marmoset (Callithrix jacchus jacchus) in its natural environment. In Biology and Behavior of Marmosets, p 298 Eds H Rothe, HJ Wolters and JP Hearn. Eigenverlag Hartmut Rothe, Gottingen

Stevenson MF and Poole TB (1976) An ethogram of the common marmoset (Callithrix jacchus jacchus): general behavioural repertoire Animal Behaviour 24 $428-451$

Stevenson MF and Rylands AB (1988) The marmosets, genus Callithrix. In Ecology of Behavior of Neotropical Primates, pp 131-122 Eds RA Mittermeier, AD Rylands, A Coimbra-Filho and GAB Fonseca. World Wildlife Fund, Washington

Summers PM, Wennick CJ and Hodges JK (1985) Cloprostenol-induced luteolysis in marmoset monkeys (Callithrix jacchus) Joumal of Reproduction and Fertility 73 133-138

Webb R, Baxter G, McBride D, Norelblom GD and Shaw MPK (1985) The measurement of testosterone and oestradiol-17 $\beta$ using iodinated tracers and incorporating an affinity chromatography extraction procedure Journal of Steroid Biochemistry 23 104-105

Wysocki CJ (1978) Neurobehavioral evidence for the involvement of the vomeronasal system in mammalian reproduction. Neuroscience Biobehaviour Reviews 3 301-341 